\title{
ROR1 is highly expressed in circulating tumor cells and promotes invasion of pancreatic cancer
}

\author{
GUI-LI XU*, JIAN SHEN*, YUN-HUA XU, WAN-SHENG WANG and CAI-FANG NI \\ Department of Interventional Radiology, First Affiliated Hospital of Soochow University, Suzhou, Jiangsu 215006, P.R. China
}

Received February 12, 2018; Accepted August 17, 2018

DOI: $10.3892 / \mathrm{mmr} .2018 .9500$

\begin{abstract}
Pancreatic cancer $(\mathrm{PaC})$ is an aggressive malignancy, which is associated with high levels of metastasis. Circulating tumor cells (CTCs), which may be considered a functional biomarker and promising treatment strategy for metastasis, are associated with the prognosis and progression of various metastatic cancers, including PaC. Receptor tyrosine kinase-like orphan receptor 1 (RORI) expression contributes to cell metastasis and poor clinical outcomes in malignant tumors. The present study aimed to explore the function of ROR1 in PaC CTCs. Reverse transcription-quantitative polymerase chain reaction and western blot analysis were used to examine the expression of RORl, E-cadherin and N-cadherin. Cell proliferative and invasive ability was assessed by MTT and Transwell assays, respectively. The results revealed that the mRNA and protein expression levels of ROR 1 were augmented in PaC tissues. Furthermore, the mRNA expression levels of $R O R I$ were higher in CTCs compared with in peripheral blood cells, and RORI was more highly expressed in CTCs than in cells. Notably, CTCs exhibited a markedly greater proliferative and invasive capacity than PANC-1 and SW-1990 cells, whereas knockdown of endogenous RORl by small interfering RNA led to suppression of the invasion of CTCs. In addition, it was revealed that the mechanism underlying the effects of $R O R l$ on PaC CTC metastasis may involve the epithelial-mesenchymal transition process. In conclusion, RORl may be considered a potential biomarker and therapeutic target for the treatment of $\mathrm{PaC}$.
\end{abstract}

Correspondence to: Professor Cai-Fang Ni or Dr Wan-Sheng Wang, Department of Interventional Radiology, First Affiliated Hospital of Soochow University, 188 Shizi Street, Suzhou, Jiangsu 215006, P.R. China

E-mail: szncf@suda.edu.cn

E-mail:wwssdfyyjrk@163.com

*Contributed equally

Key words: pancreatic cancer, circulating tumor cells, receptor tyrosine kinase-like orphan receptor 1, cell proliferation, cell invasion, epithelial-mesenchymal transition

\section{Introduction}

Pancreatic cancer $(\mathrm{PaC})$ is one of the most aggressive and lethal types of tumor, and is the fourth leading cause of cancer-associated mortality worldwide (1). Despite improvement in cancer treatment, the prognosis for patients with $\mathrm{PaC}$ remains poor, with a 5 -year survival rate of $\sim 5 \%$ (2). It has been predicted that, with its current rise in incidence, $\mathrm{PaC}$ will become the second leading cause of cancer-associated mortality by 2030 (3). The majority of patients with $\mathrm{PaC}$ are not suitable for surgical resection due to local advancement and metastasis, and the current chemotherapeutic regimens for advanced $\mathrm{PaC}$ are limited (4). The high proclivity for partial invasion and early progression to distant metastases leads to the poor outcome in $\mathrm{PaC}$ (5), thus resulting in the high mortality rate of this malignancy. Furthermore, the current biomarkers poorly predict prognosis of patients with metastatic $\mathrm{PaC}(6)$. Therefore, for the clinical treatment of this disease, the selection and identification of valid and reliable biomarkers as prognostic indicators for patients with $\mathrm{PaC}$ are important.

Circulating tumor cells (CTCs) are tumor cells that induce metastasis, which is responsible for the majority of cases of cancer-associated mortality (7). CTCs have been widely recognized as tumor- or metastasis-derived cells, which move into the circulatory system from the primary tumor site during surgical resection and lead to disease recurrence in patients with cancer (8-11). CTCs have already been widely used as a biomarker for the assessment of cancer prognosis and response to therapy (12). Previous studies have reported that CTC counts have an association with the prognosis and development of numerous metastatic diseases, including breast, colon, prostate and lung cancers (13-17). Therefore, studying CTCs may improve understanding of the potential mechanisms underlying tumorigenesis and metastasis, offer promising clinical trials for patients with metastatic cancer, and supply a target for designing effective and individualized cancer therapies.

Receptor tyrosine kinase-like orphan receptor 1 $(R O R I)$ is an embryonic protein, and a member of the ROR receptor tyrosine kinase family, which serves key roles in cell differentiation and proliferation, angiogenesis, tumor migration and metastasis (18-23). Numerous studies have indicated that RORI is expressed at high levels in various blood and solid malignancies; however, it is lowly expressed in normal adult tissues (24-27). In this regard, ROR1 protein 
may be an ideal drug target for cancer therapy; however, the underlying functions of $R O R l$ in $\mathrm{PaC}$ have yet to be elucidated.

On the basis of these findings, the present study explored the association between $R O R I$ and $\mathrm{PaC}$, and revealed that $R O R l$ was increased in $\mathrm{PaC}$ tissues compared with in noncancerous tissues. In addition, the mRNA expression levels of RORl were increased in CTCs compared with in peripheral blood cells from patients with $\mathrm{PaC}$. Furthermore, the proliferative and invasive capacity was increased in CTCs with high levels of ROR1 compared with in PANC-1 and SW-1990 cells. Furthermore, the present study revealed that downregulating RORI expression suppressed the invasive ability of CTCs. In addition, the results demonstrated that the epithelial-mesenchymal transition (EMT) process may participate in the metastasis of CTCs from primary PaC tissue. Taken together, these results suggested that RORI may be a novel genetic modifier for the progression of $\mathrm{PaC}$.

\section{Materials and methods}

PaC tissues and blood samples. A total of 25 (male; mean age, 52.6; age range 35-70 years) human $\mathrm{PaC}$ tissue and paired adjacent noncancerous pancreatic tissue samples were acquired after written informed consent was obtained from the participating patients. The patients did not receive partial or systemic treatment prior to tissue sampling, and agreed to receive these treatments at the First Affiliated Hospital of Soochow University (Suzhou, China) between June 2006 and January 2017. Paired adjacent noncancerous pancreatic tissues ( $\leq 5 \mathrm{~cm}$ from the tumor site) were obtained from patients during surgery. All tissue specimens were immediately snap-frozen in liquid nitrogen following surgery. In addition, peripheral blood specimens were obtained from patients with $\mathrm{PaC}$ using vacutainer tubes containing the anticoagulant EDTA. All peripheral blood samples were stored at $4^{\circ} \mathrm{C}$ and were processed within 3 days. The present study was approved by the Ethics Review Committee of the First Affiliated Hospital of Soochow University.

PaC cell culture. Human PaC cell lines PANC-1 and SW-1990, and the normal human pancreatic cell line HPDE6-C7 were used in the present study from the Cell Bank of the Chinese Academy of Sciences (Shanghai, China). All cells were seeded in Dulbecco's modified Eagle's medium (DMEM) (Gibco; Thermo Fisher Scientific, Inc., Waltham, MA, USA) supplemented with penicillin $(100 \mathrm{U} / \mathrm{ml})$, streptomycin $(100 \mu \mathrm{g} / \mathrm{ml})$ and $10 \%$ fetal bovine serum (FBS) (Gibco; Thermo Fisher Scientific, Inc.), and were cultured at $37^{\circ} \mathrm{C}$ in a humidified incubator containing $5 \% \mathrm{CO}_{2}$.

Isolation and culture of CTCs. Peripheral blood cells (PBCs) and CTCs were isolated and cultured with Isolation of Peripheral Blood Mononuclear Cells kit (Qiagen, Inc., Valencia, CA, USA) and the CellSearch Circulating Tumor Cell kit (Menarini Silicon Biosystems, Inc., Bologna, Italy) according to the manufacturer's protocol, respectively. The peripheral blood samples from patients with $\mathrm{PaC}$ were pooled into $10 \mathrm{ml}$ vacutainer tubes containing the anticoagulant EDTA on ice. The 2-ml peripheral blood cells were lysed in a conical tube containing $13 \mathrm{ml} 1 \mathrm{X}$ red blood cell (RBC) lysis buffer (Beijing Leagene Biotech Co., Ltd., Beijing, China) for $10 \mathrm{~min}$ at room temperature, and were then centrifuged at $800 \times \mathrm{g}$ for $8 \mathrm{~min}$ at room temperature. Subsequently, the cells were washed twice by resuspending the pellets in $6 \mathrm{ml}$ $1 \mathrm{X}$ PBS and were centrifuged at $800 \mathrm{x} \mathrm{g}$ for $3 \mathrm{~min}$ at room temperature. Finally, the remaining cells were cultured in RPMI 1640 medium (HyClone; GE Healthcare Life Sciences, Logan, UT, USA) supplemented with $10 \%$ FBS and incubated in a cell incubator containing $5 \% \mathrm{CO}_{2}$.

Reverse transcription-quantitative polymerase chain reaction $(R T-q P C R)$. Total RNA was extracted from $\mathrm{PaC}$ tissues or cells and peripheral blood cells using a HP Total RNA kit (Omega Bio-Tek, Inc., Norcross, GA, USA) and Blood RNA kit (Omega Bio-Tek, Inc.), respectively, according to the manufacturer's protocols. The RNA levels were analyzed using a NanoDrop spectrophotometer (NanoDrop; Thermo Fisher Scientific, Inc., Wilmington, DE, USA). RNA was reverse transcribed into cDNA with an M-MLV First Strand kit (Invitrogen; Thermo Fisher Scientific, Inc., Waltham, MA, USA) according to the manufacturer's protocol. The mRNA expression levels of ROR 1 were quantified using a Platinum SYBR Green qPCR SuperMix-UDG kit (Invitrogen; Thermo Fisher Scientific, Inc.) on an ABI Prism 7500 Real-Time PCR system (Applied Biosystems; Thermo Fisher Scientific, Inc., Waltham, MA, USA), according to the manufacturer's protocol. Sequences of the primers were as follows: ROR 1 (forward), 5'-AGATCACAGCTGCCTTCACTAT-3'; ROR 1 (reverse), 5'-GACATTCTCCAGGATTTCACAT-3'; $\beta$-actin (forward), 5'-GGCGGCACCACCATGTACCCT-3'; $\beta$-actin (reverse), 5'-AGGGGCCGGACTCGTCATACT-3'. The thermocycling conditions were as follows: $95^{\circ} \mathrm{C}$ for $10 \mathrm{~min}$, followed by 40 cycles of $50^{\circ} \mathrm{C}$ for $20 \mathrm{sec}$ and $60^{\circ} \mathrm{C}$ for $1 \mathrm{~min}$. Quantification cycle $(\mathrm{Cq})$ values of ROR $1 \mathrm{mRNA}$ were equilibrated to the internal control $\beta$-actin mRNA. Relative expression was calculated using the $\Delta \Delta \mathrm{Cq}$ method (28). All experiments were performed in triplicate.

Western blot analysis. Protein lysates from cells and tissues were obtained using radioimmunoprecipitation lysis buffer (Cell Signaling Technology, Inc., Danvers, MA, USA), which contained protease and phosphatase inhibitors (Sangon Biotech Co., Ltd., Shanghai, China). Protein concentrations were measured using NanoDrop technology (NanoDrop; Thermo Fisher Scientific, Inc.). Protein products $(25 \mu \mathrm{g})$ were separated by $10 \%$ SDS-PAGE and were electrophoretically transferred onto a nitrocellulose membrane (EMD Millipore, Billerica, MA, USA). The membrane was then incubated with primary antibodies at $4^{\circ} \mathrm{C}$ overnight after blocking with $1.5 \%$ bovine serum albumin (Beyotime Institute of Biotechnology, Shanghai, China), followed by incubation with secondary antibodies at room temperature for $2 \mathrm{~h}$. An Pierce ${ }^{\mathrm{TM}} \mathrm{ECL}$ Western Blotting substrate (Pierce; Thermo Fisher Scientific, Inc.) was used to detect protein bands, which were analyzed using Quantity One 4.6 software (Bio-Rad Laboratories, Inc., Hercules, CA, USA). $\beta$-actin was used to normalize target proteins. Antibodies employed in western blotting were: Rabbit anti-ROR1 (1:200, cat. no. ab15148; Abcam, Cambridge, UK), rabbit anti-E-cadherin (1:800, cat. no. ab15148; Abcam), rabbit anti-N-cadherin (1:1,000, cat. no. ab18203; Abcam), rabbit 

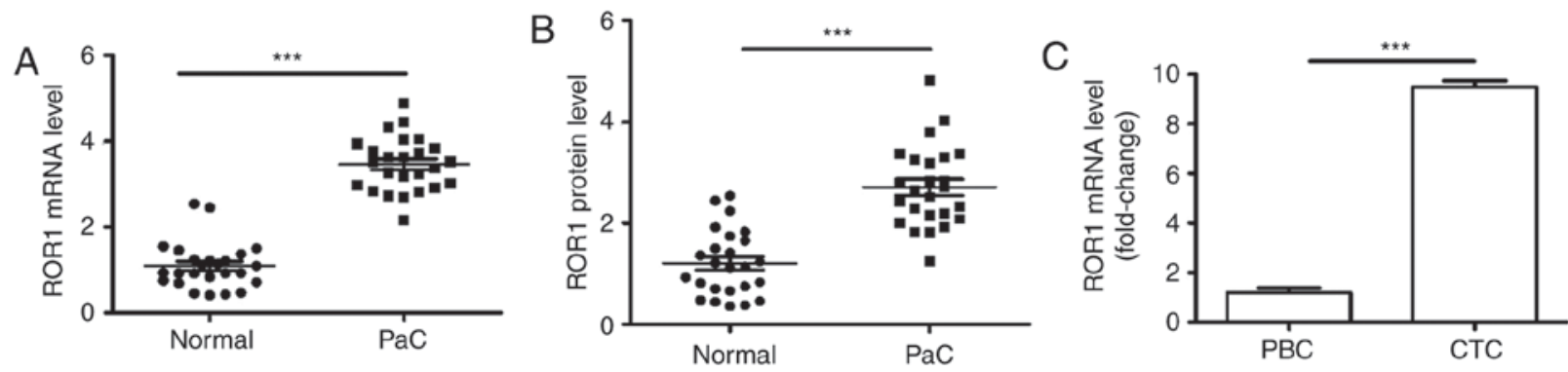

Figure 1. ROR1 expression was upregulated in PaC tissues and CTCs. (A) ROR1 mRNA expression was detected in 25 paired PaC tissues and adjacent noncancerous tissues by reverse transcription-quantitative polymerase chain reaction. (B) ROR1 protein levels were measured in 25 paired PaC tissues and adjacent noncancerous tissues by western blotting. (C) Abundance of ROR1 mRNA in CTCs compared with in PBCs. Representative data from three independent experiments were presented as the means \pm standard deviation. ${ }^{* * * *} \mathrm{P}<0.001$. CTC, circulating tumor cells; PaC, pancreatic cancer; PBC, peripheral blood cells; ROR1, receptor tyrosine kinase-like orphan receptor 1.

anti- $\beta$-actin $(1: 2,000$, cat. no. ab8227; Abcam) and mouse anti-rabbit secondary antibodies $(1: 2,000$, cat. no. sc-2357; Santa Cruz Biotechnology, Inc., Dallas, TX, USA).

RNA interference. The small interfering RNA (siRNA) sequence that directly targets human RORI and the scrambled sequence used as a corresponding negative control (NC) were synthesized by Shanghai GenePharma Co., Ltd. (Shanghai, China). The target siRNA sequence for RORl was (5'-3'): Sense, UGAACCAAUGAAUAACAUCdTdT and antisense, GAUGUUAUUCAUUGGUUCAdTdT. The NC sequence was (5'-3'): Sense, UUCUCCGAACGUGUCACGUTT and antisense, ACGUGACACGUUCGGAGAATT. CTC cells were seeded into 24 -well plates at a density of $5 \times 10^{4}$ cells/well. On the following day, CTCs were transfected with a mixture containing 100 pmol siRNA and Lipofectamine ${ }^{\circledR} 2000$ (Invitrogen; Thermo Fisher Scientific, Inc.) according to the manufacturer's protocol, incubated in a humidified atmosphere containing $95 \%$ air and $5 \% \mathrm{CO}_{2}$ at $37^{\circ} \mathrm{C}$. The cells were harvested after $72 \mathrm{~h}$ and Transwell assays were performed.

MTT assay. The proliferation of PANC-1 and SW-1990 cells, as well as CTCs obtained from patient blood samples, was assessed using MTT assay (Sigma-Aldrich; Merck KGaA, Darmstadt, Germany), according to the manufacturer's protocol. A total of 3,000 cells/well were seeded in a 96-well plate and were incubated for 4 days in a humidified atmosphere containing $95 \%$ air and $5 \% \mathrm{CO}_{2}$ at $37^{\circ} \mathrm{C}$. Subsequently, $10 \mu \mathrm{l}$ MTT reagent was added to each well and cultured at $37^{\circ} \mathrm{C}$ for $2 \mathrm{~h}$ in darkness. Dimethyl sulfoxide was added to dissolve the crystals, and the absorbance was measured at $570 \mathrm{~nm}$ every $24 \mathrm{~h}$. Three independent experiments were performed.

Transwell assay. Cell invasion assays were performed using Transwell plates (BD Biosciences, Franklin Lakes, NJ, USA) Cell invasion assays were performed in 24-well Transwell chambers containing polycarbonate filters with $8 \mathrm{~mm}$ pores coated with Matrigel. According to the manufacturer's protocol, $5 \times 10^{4}$ cells were suspended in DMEM containing $1 \%$ FBS and were placed into the top chamber, which contained a Matrigel-coated filter. DMEM supplemented with $10 \%$ FBS was added to the bottom chamber to be used as a chemoattractant. After $48 \mathrm{~h}$ at $37^{\circ} \mathrm{C}$, the DMEM was discarded and cells adhering to the upper side of the membrane were removed with a cotton swab. Cells that had invaded onto the lower side of the membrane were stained with $1 \%$ crystal violet for $30 \mathrm{~min}$ at room temperature and observed by a light microscope (magnification, x100; Olympus Corporation, Tokyo, Japan). Invasive cells were stained and counted in at least three microscopic fields (magnification, x100). The experiments were independently repeated three times.

Statistical analysis. Differences between two groups were analyzed using Student's t-test (two-tailed). Statistical analyses were conducted using GraphPad Prism 5.02 (GraphPad Software, Inc., La Jolla, CA, USA) and SPSS 16.0 software (SPSS, Inc., Chicago, IL, USA). Representative data from three independent experiments were presented as the means \pm standard deviation or means \pm standard error. $\mathrm{P}<0.05$ was considered to indicate a statistically significant difference.

\section{Results}

ROR1 expression is upregulated in PaC tissues and CTCs. Numerous studies have indicated that ROR 1 is increased in several types of blood and solid malignancies $(18,27)$. To investigate whether the expression levels of ROR 1 were elevated in PaC, ROR1 expression was detected in 25 paired $\mathrm{PaC}$ tissues and adjacent noncancerous tissues using RT-qPCR and western blotting. The mRNA expression levels of RORI in $\mathrm{PaC}$ tissues were significantly increased compared with in paired noncancerous pancreatic tissues (Fig. 1A). Furthermore, the protein expression levels of ROR1 were detected, and the results demonstrated that $\mathrm{PaC}$ tissues exhibited significantly increased ROR1 protein expression compared with in the paired noncancerous pancreatic tissues (Fig. 1B). CTCs, also known as metastasis-derived cells, move into the circulatory system from the primary tumor site. Therefore, the difference in ROR1 mRNA expression between CTCs and PaC blood cells was investigated. The results indicated that the abundance of ROR1 mRNA in CTCs was $~ 10$-fold higher compared with in peripheral blood cells obtained from patients with $\mathrm{PaC}$ (Fig. 1C). These findings indicated that RORI expression was increased in $\mathrm{PaC}$, particularly in CTCs.

Proliferative and invasive ability of CTCs is stronger than $P A N C-1$ and SW-1990 cells. Increased ROR1 expression serves key roles in cell proliferation and invasion $(18,27)$. To 
A

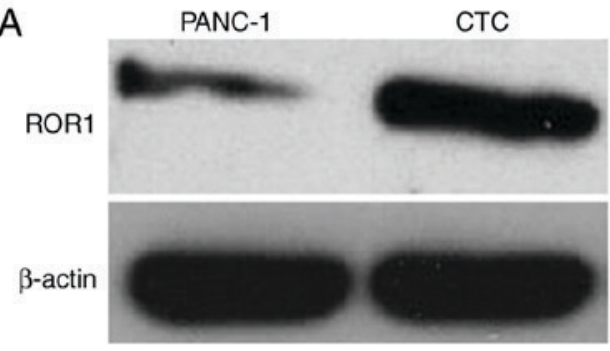

B

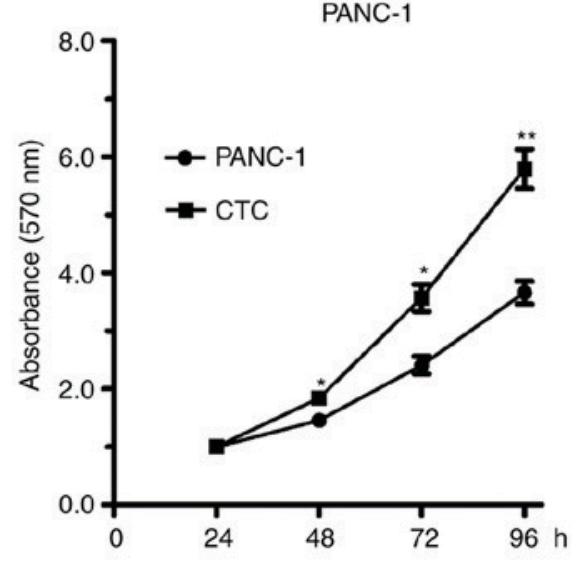

C

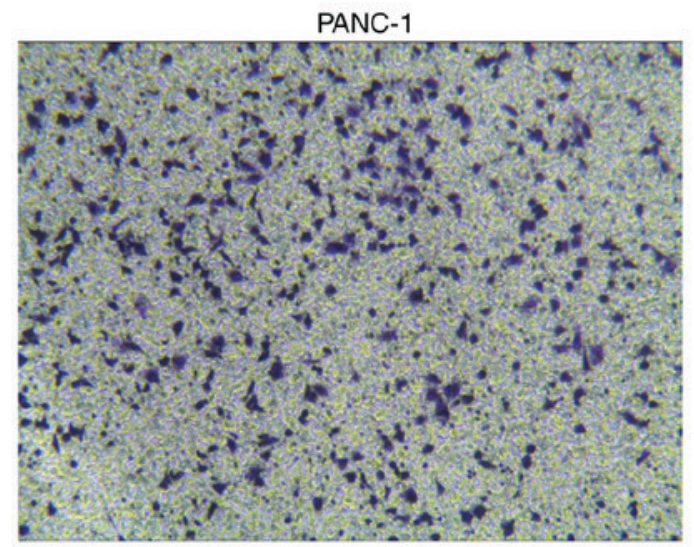

SW-1990

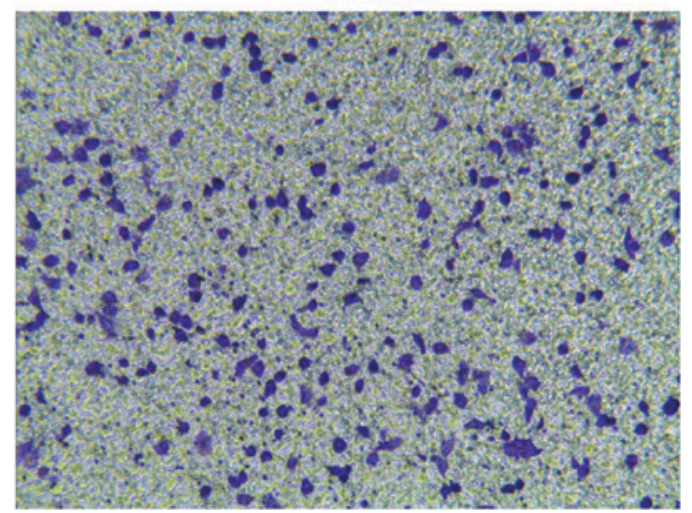

SW-1990

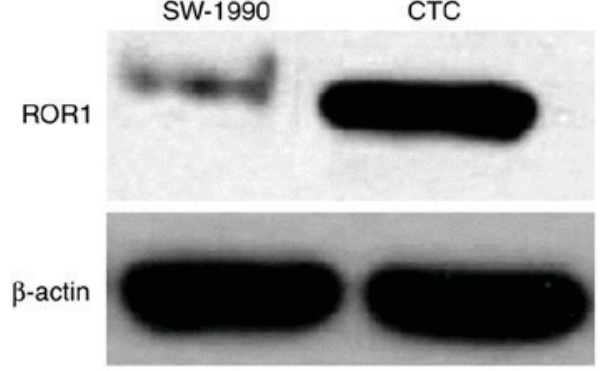

SW-1990

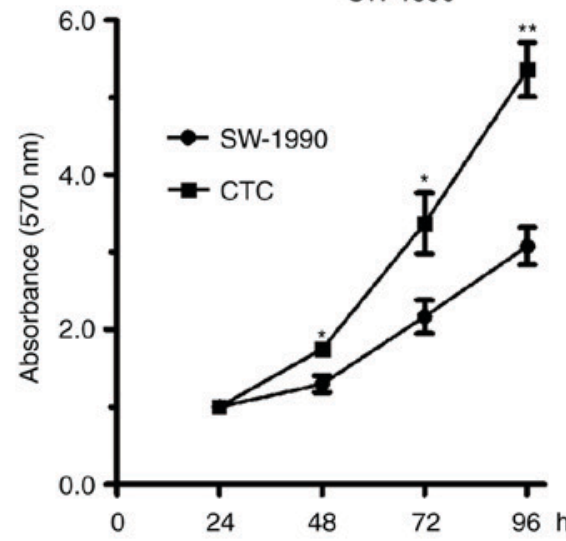

CTC

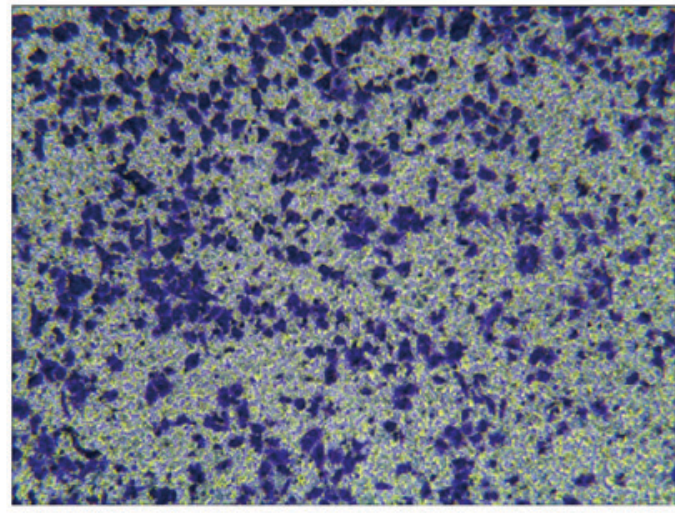

CTC

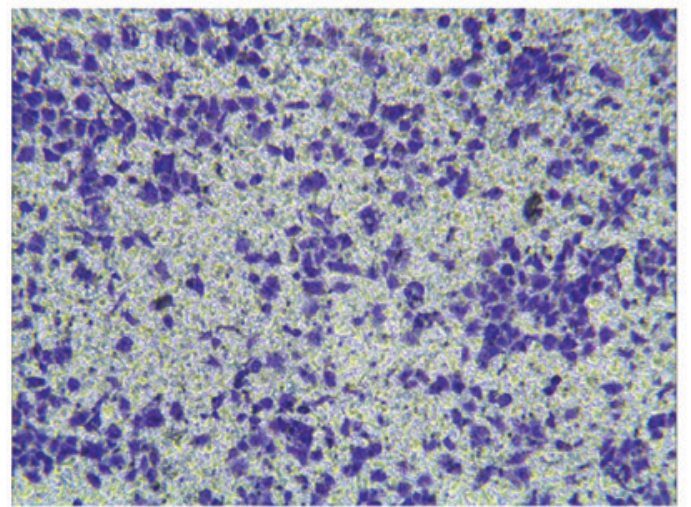

Figure 2. Proliferative and invasive ability of CTCs is stronger than PANC-1 and SW-1990 cells. (A) Western blot analysis of ROR1 in CTCs, PANC-1 and SW-1990 cells. $\beta$-actin was used as a loading control. (B) Cell proliferation of CTCs and PANC-1 and SW-1990 cells, as examined by MTT assay at the indicated time points. (C) Invasion of CTCs and PANC-1 and SW-1990 cells, as examined by Transwell assay. Invasive cells were stained and counted in at least three microscopic fields (magnification, x100). Representative data from three independent experiments were presented as the means \pm standard error. ${ }^{*} \mathrm{P}<0.05$. CTC, circulating tumor cells; ROR1, receptor tyrosine kinase-like orphan receptor 1.

investigate the role of RORI in PaC cells, and in CTC growth and invasion, MTT and Transwell assays were performed.
Initially, the expression levels of ROR1 were detected in CTCs and PANC-1 and SW-1990 cells by western blotting. 
A

ROR1

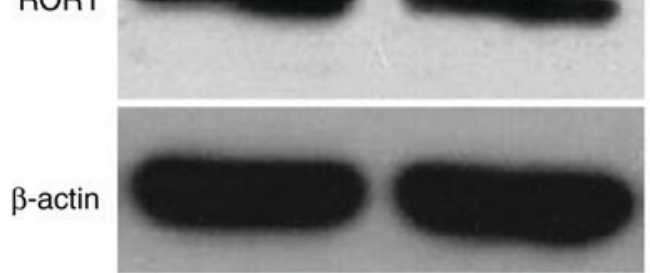

C

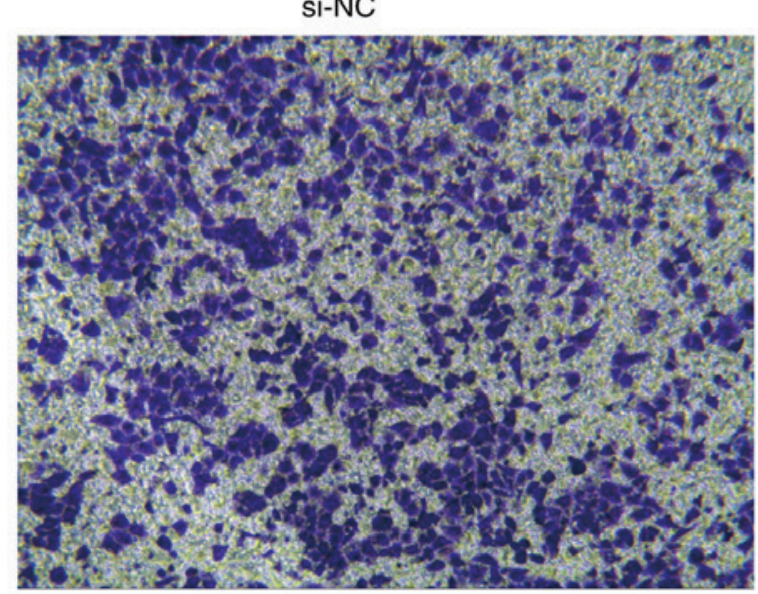

B
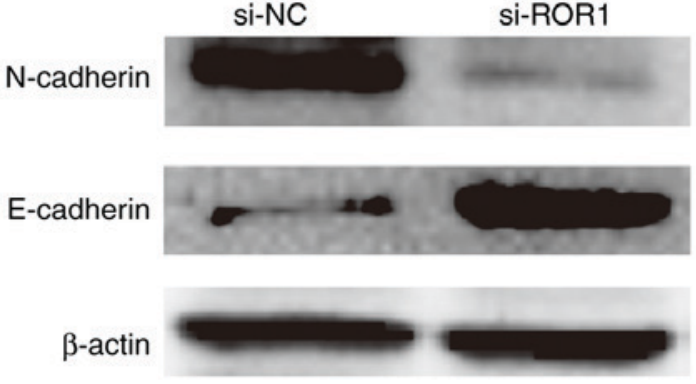

si-ROR1

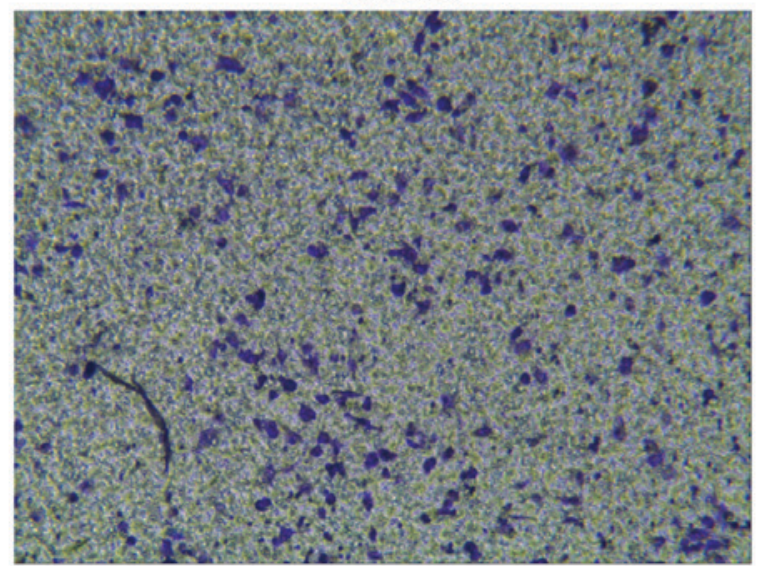

Figure 3. Knockdown of ROR1 suppresses CTC invasion. (A and B) Western blot analysis of ROR1, E-cadherin and N-cadherin in NC siRNA-transfected CTCs and ROR1 siRNA-transfected CTCs. $\beta$-actin was used as a loading control. (C) Invasion of NC siRNA-transfected CTCs and ROR1 siRNA-transfected CTCs was analyzed by Transwell assay. CTC, circulating tumor cells; NC, negative control; ROR1, receptor tyrosine kinase-like orphan receptor 1; si, small interfering RNA.

As illustrated in Fig. 2A, ROR1 expression was markedly increased in CTCs compared with in PANC-1 and SW-1990 cells. Furthermore, compared with in the PANC-1 and SW-1990 cells, CTCs with high ROR1 expression exhibited significantly higher cell viability (Fig. 2B). Consistent with the MTT assay results, CTCs with high ROR1 expression displayed enhanced cell invasive ability compared with PANC-1 and SW-1990 cells (Fig. 2C). Taken together, these results suggested that RORI may serve key roles in the ability of CTCs to mediate $\mathrm{PaC}$ growth and invasion.

Knockdown of RORl suppresses CTC invasion via regulation of the EMT process. In order to further demonstrate the role of ROR 1 in PaC metastasis, ROR 1 was knocked down in CTCs by siRNA (Fig. 3). Western blot analysis demonstrated that ROR1 expression in ROR1 siRNA-transfected CTCs was markedly reduced compared with in NC siRNA-transfected CTCs (Fig. 3A). Subsequently, a Transwell assay was performed to determine the invasive ability of ROR1 siRNA-transfected CTCs and NC siRNA-transfected CTCs cells. Knockdown of ROR 1 expression markedly prevented CTC invasion compared with in the control cells (Fig. 3C).

The present study explored the mechanism by which ROR 1 regulates cell invasion. EMT serves a key role in tumor cell invasion and metastasis (29). To investigate whether the typical molecular markers of EMT were altered, the protein expression levels of E-cadherin and $\mathrm{N}$-cadherin were examined by western blotting. RORl knockdown by siRNA increased E-cadherin protein expression, but decreased $\mathrm{N}$-cadherin protein expression in CTCs (Fig. 3B). Taken together, these results indicated that knockdown of RORI in CTCs markedly decreased the invasive ability by regulating the EMT process.

\section{Discussion}

In the present study, RORI expression was examined in $\mathrm{PaC}$ tissues and CTCs, and the roles of RORl were detected in proliferation and invasion of $\mathrm{PaC}$ cells and CTCs. In $\mathrm{PaC}$ samples, ROR1 was upregulated compared with in the paired noncancerous pancreatic tissues. Notably, the mRNA expression levels of RORl were increased in CTCs compared with in peripheral blood cells from patients with $\mathrm{PaC}$. It was also demonstrated that ROR1 levels were markedly increased in CTCs compared with in PANC-1 and SW-1990 cells. The CTCs, which were obtained from PaC blood samples and contained higher ROR1 levels, possessed stronger proliferative and invasive capabilities compared with the PaC cells, and knockdown of ROR 1 by siRNA reduced the invasive ability of CTCs. In addition, E-cadherin expression was increased and $\mathrm{N}$-cadherin expression was decreased when ROR1 was knocked down in CTCs. Therefore, the EMT process may participate in the metastasis of CTCs from primary $\mathrm{PaC}$ tissue. These findings, combined with those of previous studies (24-27), indicated that ROR1 may be a novel tool for the treatment of patients with $\mathrm{PaC}$. 
CTCs serve a crucial role in cancer development and metastasis. For example, Chang et al (30), reported that tumor marker detection could complement CTC enumeration in predicting progression in patients with metastatic castration-resistant prostate cancer. The basic biological mechanisms of CTCs in facilitating cancer development and metastasis have attracted much attention $(31,32)$. It is of great importance that highly specific molecular markers for CTC-targeted cancer therapy are identified. An increasing number of studies have reported on the expression and function of ROR1 (24-27); however, its regulatory role in CTCs from $\mathrm{PaC}$ remains largely unknown.

$R O R I$ is critically involved in the development and progression of various human cancers. In addition, ROR 1 has been reported to act as a promoter of stem cell tumorigenicity in ovarian cancer, which could be used as an indirect antagonist when its expression is decreased (33-35). In the present study, CTCs exhibited a higher proliferative and invasive potential compared with PANC-1 and SW-1990 cells, thus suggesting that ROR 1 may promote the tumorigenic process in $\mathrm{PaC}$ cells. In support of this, Cui et al (24), reported that RORI stimulates leukemia-cell activation and enhances disease progression in patients. In addition, Gentile et al (23), reported that RORI serves a key role in the malignant phenotypes maintained by the MET proto-oncogene, receptor tyrosine kinase.

In recent years, numerous methods have been applied to detect and quantify CTCs. Furthermore, the number and phenotype of CTCs, which have many similar biological characteristics, can provide information on patient prognosis and treatment efficacy (36-39). The present study demonstrated that the expression of RORl was upregulated in $\mathrm{PaC}$ tissues. Notably, the abundance of ROR 1 mRNA in CTCs from patients with $\mathrm{PaC}$ was $\sim 10$-fold higher compared with its abundance in peripheral blood cells. These findings are in accordance with previous studies, which demonstrated that RORI levels are increased in $\mathrm{PaC}$ tissues compared with in corresponding normal tissues $(20,22-24)$. However, there are some contradictory findings with regards to RORI expression in other types of cancer. For example, Balakrishnan et al (40), reported that ROR 1 is overexpressed in normal tissues compared with cancer tissues, including parathyroid tissues, pancreatic islets, and regions of the esophagus, stomach and duodenum, with resultant toxicity. These results could be explained by the finding that alterations in metabolic gene expression induced by cancer are heterogeneous in different tumor types (41). PaC is usually treated with interventional therapy, chemotherapy and radiotherapy; however, the efficacy is poor. More researchers have begun to regard molecular targeted therapy as a study focus for the acquisition of an in-depth understanding of the molecular mechanism underlying $\mathrm{PaC}$. The present results indicated that RORI could be knocked down by siRNA, which resulted in prevention of the invasion of CTCs in $\mathrm{PaC}$. A previous study suggested that the number of CTCs in the peripheral blood of patients with several types of metastatic carcinoma is positively correlated with poor clinical prognosis (42). The present results suggested that $R O R 1$ may exhibit potential for use as a screening tool to optimize the outcome of patients with $\mathrm{PaC}$, and to aid the decision of what population should be screened given the relatively low incidence, but poor survival associated with PaC. Suppressing RORI may be a potential therapeutic approach in $\mathrm{PaC}$.

In recent years, EMT, which serves a key role not only in embryonic development but also in tumor cell invasion and metastasis, has become a focus of attention (28). In the process of EMT, cell-cell junctions, polarity and epithelial cell markers are lost, which is accompanied by the gain of mesenchymal markers, and a motile and invasive phenotype, which may initiate tumor metastasis (43). Wang et al demonstrated that microRNA (miR)-30a inhibits EMT and metastasis by targeting $R O R l$, and that the downregulation of $R O R 1$ by the overexpression of miR-30a could elevate E-cadherin levels and reduce $\mathrm{N}$-cadherin expression in breast cancer (44). The present study revealed that when ROR 1 was lowly expressed, the mesenchymal marker $\mathrm{N}$-cadherin was also expressed at low levels, whereas the epithelial marker E-cadherin was highly expressed. These findings are consistent with those of previous studies and further indicated that ROR I may facilitate $\mathrm{PaC}$ metastasis by modulating the EMT process.

In conclusion, the present findings demonstrated that RORl may be associated with the metastasis of $\mathrm{PaC}$. This study furthers the understanding of the biological regulation of CTCs and suggests a novel rationale and therapeutic strategy for the diagnosis and treatment of ROR 1-positive CTCs. However, the sample size was relatively small; therefore, there is a need to further validate these results in a larger sample size. In addition, the molecular mechanisms underlying the effects of ROR1 on PaC metastasis requires further research.

\section{Acknowledgements}

Not applicable.

\section{Funding}

The present study was funded by Healthy Life Science and Technology Projects in Jiangsu Province (grant no. BL201204).

\section{Availability of data and materials}

All data generated and/or analyzed during this study are included in this published article.

\section{Authors' contributions}

GLX and JS wrote the main manuscript. GLX, JS, WSW and YHX performed the experiments. GLX, WSW and CFN designed the study. WSW and CFN analyzed the data. All authors reviewed and approved the final manuscript.

\section{Ethics approval and consent to participate}

The present study was approved by the Ethics Review Committee of the First Affiliated Hospital of Soochow University. Written informed consent was obtained from the participating patients.

\section{Patient consent for publication}

Informed consent was obtained from all patients. 


\section{Competing interests}

The authors declare that they have no competing interests.

\section{References}

1. Siegel RL, Miller KD and Jemal A: Cancer statistics, 2016. CA Cancer J Clin 66: 7-30, 2016.

2. Puleo FR, Maréchal R, Demetter P, Bali MA, Calomme A, Closset J, Bachet JB, Deviere J and Van Laethem JL: New challenges in perioperative management of pancreatic cancer. World J Gastroenterol 21: 2281-2293, 2015.

3. Ying H, Dey P, Yao W, Kimmelman AC, Draetta GF, Maitra A and DePinho RA: Genetics and biology of pancreatic ductal adenocarcinoma. Genes Dev 30: 355-385, 2016.

4. Moyer MT and Gaffney RR: Pancreatic adenocarcinoma. N Engl J Med 371: 2140, 2014.

5. Huang S, Zheng J, Huang Y, Song L, Yin Y, Ou D, He S, Chen X and Ouyang X: Impact of S100A4 expression on clinicopathological characteristics and prognosis in pancreatic cancer: A Meta-analysis. Dis Markers 2016: 8137378, 2016.

6. Ni S, Wang H, Zhu X, Wan C, Xu J, Lu C, Xiao L, He J, Jiang C, Wang W and He Z: CBX7 suppresses cell proliferation, migration, and invasion through the inhibition of PTEN/Akt signaling in pancreatic cancer. Oncotarget 8: 8010-8021, 2017.

7. Chen XX and Bai F: Single-cell analyses of circulating tumor cells. Cancer Biol Med 12: 184-192, 2015.

8. Hardingham JE, Grover P, Winter M, Hewett PJ, Price TJ and Thierry B: Detection and clinical significance of circulating tumor cells in colorectal cancer-20 years of progress. Mol Med 21 (Suppl 1): S25-S31, 2015.

9. Okegawa T, Itaya $\mathrm{N}$, Hara $\mathrm{H}$, Tambo $\mathrm{M}$ and Nutahara $\mathrm{K}$ : Epidermal growth factor receptor status in circulating tumor cells as a predictive biomarker of sensitivity in castration-resistant prostate cancer patients treated with docetaxel chemotherapy. Int J Mol Sci 17: pii: E2008, 2016.

10. Mostert B, Sieuwerts AM, Kraan J, Bolt-de Vries J, van der Spoel P, van Galen A, Peeters DJ, Dirix LY, Seynaeve CM, Jager A, et al: Gene expression profiles in circulating tumor cells to predict prognosis in metastatic breast cancer patients. Ann Oncol 26: 510-516, 2015.

11. Mego M, Giordano A, De Giorgi U, Masuda H, Hsu L, Giuliano M, Fouad TM, Dawood S, Ueno NT, Valero V, et al: Circulating tumor cells in newly diagnosed inflammatory breast cancer. Breast Cancer Res 17: 2, 2015.

12. Mego M, Gao H, Cohen EN, Anfossi S, Giordano A, Tin S Fouad TM, De Giorgi U, Giuliano M, Woodward WA, et al: Circulating tumor cells (CTCs) are associated with abnormalities in peripheral blood dendritic cells in patients with inflammatory breast cancer. Oncotarget 8: 35656-35668, 2017.

13. Gao W, Yuan H, Jing F, Wu S, Zhou H, Mao H, Jin Q, Zhao J, Cong $\mathrm{H}$ and Jia C: Analysis of circulating tumor cells from lung cancer patients with multiple biomarkers using high-performance size-based microfluidic chip. Oncotarget 8: 12917-12928, 2017.

14. de Bono JS, Scher HI, Montgomery RB, Parker C, Miller MC, Tissing H, Doyle GV, Terstappen LW, Pienta KJ and Raghavan D: Circulating tumor cells predict survival benefit from treatment in metastatic castration-resistant prostate cancer. Clin Cancer Res 14: 6302-6309, 2008

15. Chikaishi Y, Yoneda $\mathrm{K}$, Ohnaga $\mathrm{T}$ and Tanaka F: EpCAM-independent capture of circulating tumor cells with a 'universal CTC-chip'. Oncol Rep 37: 77-82, 2017.

16. Joosse SA, Gorges TM and Pantel K: Biology, detection, and clinical implications of circulating tumor cells. EMBO Mol Med 7: 1-11,2015.

17. Aggarwal C, Meropol NJ, Punt CJ, Iannotti N, Saidman BH, Sabbath KD, Gabrail NY, Picus J, Morse MA, Mitchell E, et al Relationship among circulating tumor cells, CEA and overall survival in patients with metastatic colorectal cancer. Ann Oncol 24: 420-428, 2013.

18. Liu Y, Yang H, Chen T, Luo Y, Xu Z, Li Y and Yang J: Silencing of receptor tyrosine kinase ROR1 inhibits tumor-cell proliferation via PI3K/AKT/mTOR signaling pathway in lung adenocarcinoma. PLoS One 10: e0127092, 2015.

19. Yamaguchi T, Yanagisawa K, Sugiyama R, Hosono Y, Shimada Y, Arima C, Kato S, Tomida S, Suzuki M, Osada H and Takahashi T: NKX2-1/TITF1/TTF-1-induced ROR1 is required to sustain EGFR survival signaling in lung adenocarcinoma. Cancer Cell 21: 348-361, 2012.
20. Green JL, Kuntz SG and Sternberg PW: Ror receptor tyrosine kinases: Orphans no more. Trends Cell Biol 18: 536-544, 2008.

21. Cui B, Zhang S, Chen L, Yu J, Widhopf GF II, Fecteau JF, Rassenti LZ and Kipps TJ: Targeting ROR1 inhibits epithelial-mesenchymal transition and metastasis. Cancer Res 73: 3649-3660, 2013.

22. Fukuda T, Chen L, Endo T, Tang L, Lu D, Castro JE, Widhopf GF II, Rassenti LZ, Cantwell MJ, Prussak CE, et al: Antisera induced by infusions of autologous Ad-CD154-leukemia B cells identify ROR 1 as an oncofetal antigen and receptor for Wnt5a. Proc Natl Acad Sci USA 105: 3047-3052, 2008.

23. Gentile A,Lazzari L, Benvenuti S, Trusolino L and Comoglio PM: Rorl is a pseudokinase that is crucial for Met-driven tumorigenesis. Cancer Res 71: 3132-3141, 2011.

24. Cui B, Ghia EM, Chen L, Rassenti LZ, DeBoever C, Widhopf GF II, Yu J, Neuberg DS, Wierda WG, Rai KR, et al: High-level ROR1 associates with accelerated disease progression in chronic lymphocytic leukemia. Blood 128: 2931-2940, 2016.

25. Henry C, Llamosas E, Knipprath-Meszaros A, Schoetzau A, Obermann E, Fuenfschilling M, Caduff R, Fink D, Hacker N, Ward R, et al: Targeting the ROR 1 and ROR2 receptors in epithelial ovarian cancer inhibits cell migration and invasion. Oncotarget 6: 40310-40326, 2015.

26. Borcherding N, Kusner D, Liu GH and Zhang W: ROR1, an embryonic protein with an emerging role in cancer biology. Protein Cell 5: 496-502, 2014.

27. Henry CE, Llamosas E, Djordjevic A, Hacker NF and Ford CE: Migration and invasion is inhibited by silencing ROR 1 and ROR2 in chemoresistant ovarian cancer. Oncogenesis 5: e226, 2016.

28. Livak KJ and Schmittgen TD: Analysis of relative gene expression data using real-time quantitative PCR and the 2(-Delta Delta C(T)) method. Methods 25: 402-408, 2001.

29. Gal A, Sjöblom T, Fedorova L, Imreh S, Beug H and Moustakas A: Sustained TGF beta exposure suppresses Smad and non-Smad signalling in mammary epithelial cells, leading to EMT and inhibition of growth arrest and apoptosis. Oncogene 27: 1218-1230, 2008.

30. Chang K, Kong YY, Dai B, Ye DW, Qu YY, Wang Y, Jia ZW and Li GX: Combination of circulating tumor cell enumeration and tumor marker detection in predicting prognosis and treatment effect in metastatic castration-resistant prostate cancer. Oncotarget 6: 41825-41836, 2015.

31. Pantel K and Alix-Panabieres C: Functional studies on viable circulating tumor cells. Clin Chem 62: 328-334, 2016.

32. Hamilton $G$ and Rath B: Detection of circulating tumor cells in non-small cell lung cancer. J Thorac Dis 8: 1024-1028, 2016.

33. Zhang S, Cui B, Lai H, Liu G, Ghia EM, Widhopf GF II, Zhang Z, Wu CC, Chen L, Wu R, et al: Ovarian cancer stem cells express ROR1, which can be targeted for anti-cancer-stem-cell therapy. Proc Natl Acad Sci USA 111: 17266-17271, 2014.

34. Reinholz MM, Kitzmann KA, Tenner K, Hillman D, Dueck AC, Hobday TJ, Northfelt DW, Moreno-Aspitia A, Roy V, LaPlant B, et al: Cytokeratin-19 and mammaglobin gene expression in circulating tumor cells from metastatic breast cancer patients enrolled in North Central Cancer Treatment Group trials, N0234/336/436/437. Clin Cancer Res 17: 7183-7193, 2011

35. Hojjat-Farsangi M, Moshfegh A, Daneshmanesh AH, Khan AS, Mikaelsson E, Osterborg A and Mellstedt $\mathrm{H}$ : The receptor tyrosine kinase ROR1-an oncofetal antigen for targeted cancer therapy. Semin Cancer Biol 29: 21-31, 2014.

36. Farace F, Massard C, Vimond N, Drusch F, Jacques N, Billiot F Laplanche A, Chauchereau A, Lacroix L, Planchard D, et al: A direct comparison of CellSearch and ISET for circulating tumour-cell detection in patients with metastatic carcinomas. $\mathrm{Br}$ J Cancer 105: 847-853, 2011.

37. van de Stolpe A, Pantel K, Sleijfer S, Terstappen LW and den Toonder JM: Circulating tumor cell isolation and diagnostics: Toward routine clinical use. Cancer Res 71: 5955-5960, 2011.

38. Danila DC, Anand A, Sung CC, Heller G, Leversha MA, Cao L, Lilja H, Molina A, Sawyers CL, Fleisher M and Scher HI: TMPRSS2-ERG status in circulating tumor cells as a predictive biomarker of sensitivity in castration-resistant prostate cancer patients treated with abiraterone acetate. Eur Urol 60: 897-904, 2011. 
39. Barriere G, Fici P, Gallerani G, Fabbri F, Zoli W and Rigaud M Circulating tumor cells and epithelial, mesenchymal and stemness markers: Characterization of cell subpopulations. Ann Transl Med 2: 109, 2014.

40. Balakrishnan A, Goodpaster T, Randolph-Habecker J, Hoffstrom BG, Jalikis FG, Koch LK, Berger C, Kosasih PL, Rajan A, Sommermeyer D, et al: Analysis of ROR1 protein expression in human cancer and normal tissues. Clin Cancer Res 23: 3061-3071, 2017.

41. Hu J, Locasale JW, Bielas JH, O'Sullivan J, Sheahan K, Cantley LC, Vander Heiden MG and Vitkup D: Heterogeneity of tumor-induced gene expression changes in the human metabolic network. Nat Biotechnol 31: 522-529, 2013.
42. Hou JM, Krebs MG, Lancashire L, Sloane R, Backen A, Swain RK, Priest LJ, Greystoke A, Zhou C, Morris K, et al: Clinical significance and molecular characteristics of circulating tumor cells and circulating tumor microemboli in patients with small-cell lung cancer. J Clin Oncol 30: 525-532, 2012.

43. Yang $\mathbf{J}$ and Weinberg RA: Epithelial-mesenchymal transition: At the crossroads of development and tumor metastasis. Dev Cell 14: 818-829, 2008.

44. Wang X, Qiu H, Tang R, Song H, Pan H, Feng Z and Chen L: miR-30a inhibits epithelialmesenchymal transition and metastasis in triple-negative breast cancer by targeting ROR1. Oncol Rep 39: 2635-2643, 2018. 